\title{
TERRITÓRIO E POLÍTICA: PRÁXIS INVERTIDAS E DESAFIOS DA EXISTÊNCIA
}

\section{Territory and politics:Inverted praxis and existence challenges}

Mirlei Fachini Vicente Pereira Professor Adjunto, cursos de Graduação e Pós-Graduação em Geografia, IG-UFU

Uberlândia/MG - Brasil mirlei@ig.ufu.br

Artigo recebido para publicação em 10/12/2010 e aceito para publicação em 24/03/2011

RESUMO: A intenção do artigo é resgatar as potencialidades analíticas do conceito "território" enfatizando o seu caráter político. Parte-se da idéia de que o território hoje é alvo de práticas nem sempre endereçadas às necessidades da nação, configurando assim "práxis invertidas" de uso do território. Uma compreensão integra e totalizadora do espaço aparece como um desafio, em que a existência de todos os agentes e as possibilidades de novos projetos possam ser levados em conta na análise territorial.

Palavras-chave: Território usado. Política. Alienação. Existência.

ABSTRACT: The aim of this article is to retrieve the analytical potentialities of the concept of "territory", stressing its political character. It starts from the idea that territory today is an object of practices not always addressed to the nation's need, thus, configuring "inverted praxis" of territory usage. A complete and totaliser understanding of space appears as a challenge, in which the existence of all the agents and possibilities of new projects may be taken into account in the territorial analysis.

Keywords: Used territory. Politics. Alienation. Existence.

“(...) os fatos sociais ainda não são de modo nenhum os produtos da liberdade humana, mas resultados naturais da atuação cega de forças antagônicas "

Max Horkheimer, 1933. 


\section{TERRITÓRIO - CENTRALIDADE E RESGATE DE UMA CATEGORIA}

No período histórico atual, as preocupações com as questões territoriais se renovam e se intensificam, o que confere uma importância ainda maior à categoria território e à própria ciência geográfica.

O pensamento único que preside o processo atual de globalização, portador do discurso hegemônico que elege e valoriza a economia como fundamento primeiro da organização social, aos poucos se revela como projeto falacioso (SANTOS, 2000). As promessas fabulosas de unificação facilitada dos mercados e de uma fluidez e de uma integração vantajosas para as nações dão hoje claros sinais de que tal integração e tal fluidez existem de fato para poucos agentes. Os discursos de "fim da história", de "prevalência do tempo sobre o espaço" e de "desintegração das fronteiras" são hoje desmentidos, carecem de revisão, e é o próprio território que constitui o dado central para a desmistificação de tais discursos alienantes. Temos diante de nós um recurso analítico válido para repensarmos o espaço geográfico e sua dimensão política, esforço que deve levar em conta todas as possibilidades de realização do futuro.

Tal situação revigora nossa disciplina e mesmo coloca a geografia num contexto de maior importância entre o conjunto dos saberes. "Não há projeto realista sobre o futuro político - falando em termos da vida social - que se possa fazer sem a geografia, sem a análise do espaço" (SILVEIRA, 2006, p.87). Para tanto, será necessário enfrentarmos o desafio de repensar nossas preocupações analíticas e redimensioná-las de forma a operacionalizar uma análise substantiva do território, ou seja, uma análise do território tal como ele existe, tal como ele se constitui, uma análise que seja ao mesmo tempo capaz de oferecer a compreensão dos fenômenos contemporâneos e capaz de indicar as ferramentas políticas para a necessária construção de um mundo mais justo. A tarefa primeira parece ser a de recompor a compreensão do território, que constitui analiticamente um conceito importante e, empírica e epistemologicamente, constitui um objeto privilegiado de análise.

\section{TERRITÓRIO E POLÍTICA, ONTEM E HOJE}

Todo o esforço de análise pressupõe a existência de um método e de um corpo teórico e conceitual capazes de oferecer uma operacionalidade eficaz na análise das situações empíricas. É com esse intuito que as ciências elaboram todo um sistema articulado de referências e idéias, um conjunto de categorias e conceitos que nos permitem teorizar a realidade.

É assim que a categoria território, desde F. Ratzel até os dias de hoje, constitui importante recurso conceitual e oferece um quadro de referência válido para a análise do espaço geográfico, quando se leva em consideração a importância da política.

Entretanto, não há como tomar o conceito de território tal como Ratzel o fizera no século XIX, ao mesmo tempo em que não há como desconsiderar o papel da política quando se pensa em território. É por isso que "(...) a datação do mundo faz com que tenhamos sempre que estar revendo conceitos" (SANTOS, 1999, p.25), visto que “(...) os conceitos têm uma duração histórica, são datados. Eles também morrem e, junto com eles, uma disciplina que não se renova" (SILVEIRA, 2003, p.409).

Mas repensar o território e tomá-lo como um conceito operacional à análise dos fenômenos, tal como eles se apresentam na atualidade, implica reconhecermos os seus fundamentos, ou seja, suas bases comuns que, ainda que em constante transformação, lhe conferem status de uma categoria analítica válida.

O território é, ainda hoje, categoria da geografia que expressa questões políticas do espaço, tal como reconheceram geógrafos como Frederic Ratzel e Camille Vallaux, desde a virada do século XIX para o XX (RAFFESTIN, 1980, 1993; COSTA, 1992). Assim, ao pensarmos o território, pensarmos o território como conceito, conceito oportuno à análise desta totalidade que é o espaço geográfico, a idéia de política e a idéia de poder aparecem como seus fundamentos privilegiados, fundamentos estes que atravessam períodos e garantem a possibilidade de se falar em território até os dias de hoje.

Noções e idéias herdadas, no entanto, carecem de revisão histórica. A geografia deve à reflexão de Ratzel as compreensões que, desde o final do século XIX, estabelecem os nexos entre território e política, 
sendo para Ratzel o Estado Nacional o ator político por excelência - daí a geografia política clássica estabelecer-se como uma "geografia política dos Estados" (RAFFESTIN, 1993). Disso também resulta, até os dias de hoje, as tantas insistências em tomar o "território" como o recorte espacial exclusivo do Estado Nação, como se a sua escala geográfica de ocorrência fosse apenas a escala do país.

Mesmo nesta concepção tradicional, exclusivamente ligada ao Estado e à sua política, a idéia de território aparece como aquele chão ou solo em que determinado Estado Nação exerce a sua soberania, com toda a implicação política e geopolítica do raciocínio ratzeliano que acompanha os conceitos de território e de Estado pautados mesmo numa analogia orgânica/ biológica (daí a teoria do "Espaço Vital" em Ratzel).

No período atual, quando o meio técnico-científico-informacional possibilita a redefinição dos sistemas políticos e das estratégias de ação, o território ganha uma nova conotação, tal como Milton Santos já reconhecera - "O território era a base, o fundamento do Estado-Nação que, ao mesmo tempo o moldava. Hoje, quando vivemos uma dialética do mundo concreto, evoluímos da noção, tornada antiga, de Estado Territorial para a noção pós-moderna de transnacionalização do território" (SANTOS, 1994, p.15).

Ainda que os discursos pós-modernos e pretensiosos da globalização hegemônica queiram a todo tempo minimizar o papel das fronteiras e da política para a compreensão do mundo e da face contemporânea das questões territoriais, a dimensão política do território (enquanto categoria analítica) se fortalece e caracteriza mesmo o seu fundamento. Esta dimensão política se repete e se atualiza em muitas das conceituações recentes de território, ainda que a escala de análise não mais se restrinja à do território nacional, do mesmo modo como o Estado já não aparece como agente político-territorial único ou privilegiado.

O território, que abrange todas as esferas de ação, em todas as dimensões de seu uso, pode ser compreendido, no dizer de Milton Santos (1996), como "território usado", "espaço banal", espaço de todos - todo o espaço geográfico. Isso remete a compreendermos o espaço geográfico como um conjunto indissociável e contraditório de sistemas de objetos e sistemas de ações (todos os objetos e todas as ações), como a comunhão e a inseparabilidade daquilo que é material e daquilo que é imaterial, entre tecnoesfera e psicoesfera (SANTOS, 1996).

Assim, para que a análise geográfica seja válida na compreensão do mundo hoje, o conceito de território deve ser renovado considerando-se a indissociabilidade dos sistemas de ações e da materialidade da vida das sociedades. "Nada fazemos hoje que não seja a partir dos objetos que nos cercam", e temos ainda de levar em conta que, "(...) enquanto os outros especialistas podem escolher, na listagem de ações e na população de objetos, aqueles que interessam aos seus estudos setoriais, o geógrafo é obrigado a trabalhar com todos os objetos e todas as ações" (SANTOS, 1996, p.257), ou seja, temos de considerar quais são os conteúdos do território; do que ele é constituído; quais objetos e ações o animam; quais são os seus usos e quais as implicações deles resultantes.

Ainda que de forma pouco explícita, tais preocupações já aparecem na geografia política de Ratzel, visto que a dimensão e os interesses políticos sobre o território, por parte dos estados nacionais, não podem ser outros senão aqueles voltados para a detenção de recursos estratégicos, de controle sobre as regiões menos ou mais povoadas ou equipadas com diferentes objetos ou recursos. É assim, portanto, um interesse sobre o conteúdo do território, sobre aquilo que ele de fato significa e sobre as suas potencialidades, concepção esta mais tarde reforçada por Camille Vallaux (1911). Essa preocupação com o conteúdo e os usos do território de modo algum eximem a dimensão política do conceito, pelo contrário - valorizam e reforçam a dimensão ao mesmo tempo material e política do território. "Não há existência que se defina sem considerar esse prático-inerte. Não há situação concreta que não seja construída sem a mediação dessa ação cristalizada" (SILVEIRA, 2006, p.87).

Insistimos, aqui, na inseparabilidade das dimensões material e imaterial do território para a análise geográfica (SANTOS, 1996), visto que uma série de estudos em geografia tem apresentado atualmente o tema do território (e das territorialidades) como o uso (ou "apropriação") momentâneo ou mesmo exclusivamente simbólico/afetivo do espaço, por grupos ou agentes específicos. A apropriação pela geografia de tais idéias (no mais das vezes tomadas da 
Antropologia e da Filosofia, sem o necessário reparo intelectual interno) é um convite ao erro de deixar em segundo plano a dimensão material do território. Tal dimensão material, aqui, não se trata de uma materialidade "reducionista" (empirista), mas aquela que define mesmo a concretude histórica e social de nosso objeto de análise. Nas palavras de Carlos W. Porto-Gonçalves, "A sociedade se territorializa sendo o território sua condição de existência material. É preciso recuperar essa dimensão material, sobretudo nesse momento como o que vivemos em que se dá cada vez mais importância à dimensão simbólica, quase sempre de modo unilateral, como se o simbólico se opusesse ao material" (PORTO-GONÇALVES, 2002, p.311).

Assim, uma postura crítica frente às situações que presentemente ocorrem, sobretudo nos países pobres onde persistem as desigualdades sociais, passa a figurar como um dever do geógrafo comprometido com a compreensão das mazelas que afligem o cotidiano dos territórios nacionais, exigindo-nos esforços para a produção de um discurso forte, válido na busca das necessárias transformações das estruturas de tomada de decisão e de formulação das estratégias de ação. A construção de um território mais justo passa pelo seu conteúdo geográfico - não há projeto para o território que se possa fazer sem a geografia, sem a análise constitucional do território (SILVEIRA, 2006, 2008). Não há como pensar um futuro outro sem nos atermos à política que define e orienta os usos possíveis do território. Assim, toda a geografia deve ser de certo modo uma geografia política, porque a política é inerente ao território usado. "Não há como explicar o território sem o seu uso. Não há como explicar o uso do espaço sem sua dimensão política. É essa condição híbrida que faz do território usado uma categoria central para a formulação de uma teoria social" (SILVEIRA, 2008, p.25).

A idéia de território usado, tão cara à proposta de Milton Santos (1994, 1996), aparece como instrumento analítico (e ao mesmo tempo político) valioso. Daí podermos fazer distinção analítica entre uso do território como recurso e território usado. O uso do território como recurso (SANTOS, 2000) pode ser compreendido, no mais das vezes, como resultado de projetos particulares, orientados por uma razão que tem vistas somente para finalidades específicas e previamente (racionalmente) determinadas, aparecendo assim como um uso indiferente ao meio próximo, alheio ao meio circundante. É quando prevalece um único ator político, uma ação setorial, ou um conjunto seleto de agentes. O uso do território como recurso atesta, no mais das vezes, o espaço econômico nos termos propostos por François Perroux em meados do século XX.

A noção de território usado, por sua vez, impõe pensarmos o território em sua totalidade - espaço banal, espaço de todos, todo o espaço (SANTOS, 1996; BERNARDES et al. 2000). Para além do espaço reticular e racional da ação hegemônica, o território, quando compreendido como território usado, contempla necessariamente todos os usos, todos os interesses, todas as políticas e todas as razões de ser (e de existir), constituindo assim um recurso analítico pleno de caráter político e humanista.

Quando tomamos apenas uma parte dos objetos, quando descuidadamente avaliamos apenas uma parcela das ações no território, corremos o grave risco de nos alienarmos do restante dos processos, de nos alienarmos da totalidade do acontecer no território. $\mathrm{Ou}$ ainda, e o que é mais grave, quando a análise é a priori e pretensiosamente realizada de forma fragmentada, tal alienação não é risco, é projeto - pretende-se tomar a parte como se fosse o todo, a economia e a produção hegemônicas como se essas fossem toda a produção, o espaço das redes e o espaço econômico como se fosse todo o espaço geográfico, pretende-se comprovar a partir de informações parciais aquilo que é mais do que uma parte, ou mesmo, a partir de argumentos seletos e restritos, iludir e convencer (com análises que não levam em conta o território na sua totalidade) a adesão social à uma "gestão" limitada, que toma o lugar da política ampla e democrática, promovendo assim a aceitação dos planejamentos elitistas e do uso corporativo do território.

A análise do território hoje, quando se pretende politicamente justa e capaz de elaborar um discurso e uma epistemologia comprometidos com a transformação das estruturas vigentes precisa ser fiel a tal dimensão totalizadora do território. Quando esta totalidade não é levada em conta é a alienação que impera na análise e a orientação dos usos territoriais torna-se algo como uma "práxis invertida", que toma 
o lugar da verdadeira práxis. Não é isso que aparece em tantas análises, planos, projetos de intervenção e propostas políticas firmadas em função de interesses corporativos e restritos?

\section{GLOBALIZAÇÃO PERVERSA E TERRITÓRIO ALIENADO - AS PRÁXIS INVERTIDAS}

A análise parcial, as abordagens seletivas e a consideração exclusiva da política e da economia hegemônicas resultam na negação às possibilidades de mudança. Quando se aceitam as situações vigentes, nega-se o futuro enquanto possibilidade de transformação. É isso o que os agentes da globalização hegemônica querem impor a todo tempo, é isto o que muito governantes e planejadores (investidos das razões corporativas e privadas) querem estender à maioria das práticas políticas no território.

O fundamento político da análise territorial acaba, tantas vezes, restrito à política das grandes empresas - é como se os macroatores da economia (grandes corporações, bancos, grandes grupos econômicos) e da política (Estados ricos e privilegiados, FMI, BIRD, etc.), que hoje tanto se confundem (política das empresas e gestão pública), fossem os únicos a oferecer os "remédios possíveis", ou, ainda, como se eles fossem os únicos capazes de ditar as ações, propor o futuro. Numa inversão total dos propósitos, tais agentes da economia hegemônica, por sua potência e poder, acabam figurando com exclusividade como a parcela "ativa" da nação, justamente porque compõem aquela parcela que mais significativamente aparece na “contabilidade nacional" (SANTOS, 2000).

Se nossas análises valorizam exclusivamente tais agentes, se nossas preocupações se voltam para a tarefa de operacionalizar e propor o desenvolvimento a partir dos interesses de tais agentes, nosso trabalho torna-se um verdadeiro convite à legitimação das práticas corporativas deste período. Temos, assim, uma teoria elitizada e parcial, incapaz de reconhecer a experiência social como um todo, já que as análises e os enfoques se direcionam (ou são posicionados) para a compreensão de práticas também parciais. Em outras palavras - a dimensão política do território deve ser maior do que apenas aquela restrita à política econômica hegemônica e corporativa, que legitima e dá suporte ao processo perverso de globalização atual.

Tanto o território nacional quanto os lugares se tornam vítimas de discursos e práticas corporativos. Perde-se a dimensão do trabalho voltado aos interesses verdadeiramente coletivos, da distinção entre o que é público e o que é privado e das políticas que, verdadeiramente, potencializam a práxis social transformadora.

Não se trata da apregoada "morte" do Estado, nem mesmo do seu suposto enfraquecimento, já que o Estado participa de modo fundamental na regulação do território, e ainda é, por excelência, o principal agente formulador das normas políticas que orientam os usos territoriais. O que ocorre é um "casamento perfeito" entre os interesses das grandes empresas e as políticas promovidas pelo Estado, nos seus diferentes níveis, constituídas para viabilizar a ação hegemônica no território da nação. Daí, tantas vezes, o império de interesses externos e alheios às sociedades nacionais, a entrega facilitada dos recursos públicos, os projetos que viabilizam a transformação do território nacional num "espaço nacional da economia internacional" (SANTOS, 1996, p.194).

Trata-se de uma inversão dos propósitos, um território alienado onde há lugar para uma "práxis invertida" (e por isso uma falsa práxis) (SANTOS, 2008), porque parte significativa da sociedade e das políticas da nação se presta à realização do trabalho e de projetos que lhes são estranhos. É uma práxis invertida porque, ao invés de constituir-se como ação orientada para a construção livre e autônoma do território, se apega aos mandamentos de uma lógica corporativa que promove a expansão e o fortalecimento dos nexos capitalistas, capazes de erigir uma configuração territorial que lhe dá suporte. É toda a força da presentificação do território, um conjunto de modernizações que o atualizam, uma expansão do meio técnico-científico-informacional (SANTOS, 1994, 1996) que se coloca como um problema do território e da nação porque, como adverte María Laura Silveira (2008, p.25), “(...) não se faz sem a força ou a fraqueza da soberania política de uma nação".

É como se a sociedade, ou pelo menos parte importante dela (sobretudo aqueles que manipulam, legítima ou ilegitimamente a política, o direito e a administração), optasse por induzir esforços que apre- 
sentam, com eloqüência, tal discurso como possibilidade única de gestão e como forma vantajosa de tornar viável a ação econômica pragmática no território. Não será este o caso de todo um esforço para a desconstrução dos embates sociais e das lutas de classe, como bem retrata o trabalho de Teixeira (2008), embates que hoje tantas vezes dão lugar aos discursos e práticas da "colaboração" - entre trabalhadores e detentores do capital, entre agentes que antes praticavam a concorrência, entre tão diferentes Estados nacionais que, agora, alinham discursos e políticas que favorecem o incremento e a hegemonia do capital financeiro? "Onde antes existia concorrência, esta foi substituída pela parceria; onde havia o monopólio e o segredo da produção se põe a troca; onde havia intrigas, surge a colaboração. Os porta-vozes da economia vulgar tornaram-se cínicos" (TEIXEIRA, 2008, p.115).

A dimensão territorial do problema se torna nítida quando observamos os empenhos em dotar o território de um conjunto de objetos modernos e de ações estrategicamente elaboradas para a realização do trabalho e das atividades que se voltam, quase que exclusivamente, para atender demandas externas, necessidades corporativas. Tal como na compreensão de Marx (1844, 2008, p.83), para quem o trabalho não garante de fato a satisfação das carências e se realiza apenas para satisfazer necessidades estranhas ao homem, o território também se aliena, porque as atividades nele realizadas se voltam para a satisfação de necessidades que lhe são estranhas. É de uma alienação territorial que se trata, quando especializações regionais/territoriais impõem nexos externos comandados por um mercado distante, como bem reconhece Milton Santos (1975, 2003, p.145), quando os usos do território se dão muito em função de propósitos alheios ao cotidiano da nação, quando as atividades se invertem visando atender apenas demandas distantes cujo controle é remoto e, sobretudo hoje, quando o território nacional se torna alvo e refém de um capital financeiro globalizado que, por princípio, não tem compromisso moral com lugar algum.

Com o monitoramento telecomandado do processo de produção, o capital financeiro tornou-se o centro cerebral de todo o processo de valorização, porque pode, agora, vigiar e comandar os investimentos de qualquer lugar do mundo, deslocando massas de valor de um negócio para outro, sempre que as oscilações das moedas nacionais abrem oportunidade de ganhos extras. Não sem razão, o processo de produção do valor transforma-se numa grande montanha de papel, na qual são registradas as informações sobre as diferentes taxas de câmbios e juros, de ações em todo o mundo. Dai a necessidade de o capital contar com uma rede de profissionais espalhados por todo o mundo, de plantão 24 horas por dia, sempre prontos a informar, a qualquer tempo, a melhor oportunidade de investimento (TEIXEIRA, 2008, p.136).

Este tipo de ação é possibilitado por um aparato técnico-informacional construído e colocado à disposição de agentes econômicos globais que praticam um uso vantajoso do território, extraindo uma "mais-valia tornada universal", manifestação mais acabada daquilo que Milton Santos (2000) reconhece como a emergência de um "motor único do capitalismo", ao mesmo tempo em que se empreende uma busca desenfreada pelo "dinheiro em estado puro", verdadeira meta política das grandes empresas e das nações. "O resultado objetivo é a necessidade, real ou imaginada, de buscar mais dinheiro, e, como este, em seu estado puro, é indispensável à existência das pessoas, das empresas, das nações, as formas pelas quais ele é obtido, sejam quais forem, já se encontram antecipadamente justificadas"(SANTOS, 2000, p.56).

Se o resultado do trabalho realizado num lugar não se reverte em beneficio do próprio lugar, se não pertence ao próprio lugar, e se as atividades no território nacional não são feitas em função das suas próprias carências (configurando uma atividade estranha, forçada por uma injusta divisão do trabalho), temos, de fato, um território alienado, um desvio ou uma ausência de projeto. É quando o território da nação é tomado unicamente como recurso, alienado assim de tal modo que regiões e lugares, comandados por interesses alheios, se tornam incapazes de guiar-se por si próprios. É deste modo que “(...) as noções de alienação e de mistificação não têm precisamente sentido senão na medida em que roubam os fins e os desqualificam" (SARTRE, 1979, p.130). 
Tal alienação também fora reconhecida por Isnard (1982), autor que utiliza o conceito de espaços alienados “(...) para designar regiões que devem ao exterior, não só a sua criação e a sua integração no mercado mundial, mas ainda a sobrevivência da sua organização, enfim, regiões cuja população indígena jamais controla, e que até os próprios poderes públicos dificilmente controlam" (ISNARD, 1982, p.55).

Fruto de uma organização alienada e com origem em práxis invertidas que legitimam e colaboram para a apropriação corporativa dos recursos socialmente construídos, o território, especialmente nos países pobres, assiste a formação de verdadeiras "regiões fictícias" (WETTSTEIN, 1992, p.39), constituídas e voltadas para os nexos com o mercado externo que, numa organização extravertida (SANTOS; SILVEIRA, 2001), respondem quase que exclusivamente aos mandos de um conjunto seleto de agentes internacionais que são também os portadores dos discursos da "modernização necessária", do "crescimento e desenvolvimento" necessários para a nação, fazendo com que necessidades corporativas sejam confundidas e figurem como necessidades coletivas, e que seus projetos individuais apareçam como um "projeto para a nação". Disto, criam-se especializações territoriais extremadas, cuja exteriorização ou abertura é, de fato, uma verdadeira alienação (SANTOS; SILVEIRA, 2001, p.301).

A idéia de alienação do território também pode ser claramente identificada nos casos em que o mesmo é alvo de uma adaptação técnica (infra-estruturas) e normativa (regulações especiais, isenções fiscais) para a atração de investimentos que, no entanto, acabam por torná-lo refém do poder econômico de grandes empresas que, uma vez instaladas, passam a dominar as políticas locais ou mesmo as nacionais, tal como avalia Márcio Cataia (2003, p.402).

O território alienado é, assim, a forma histórica concreta (o território e suas práxis invertidas) que materializa ações e realiza esforços de uma alienação territorial, esta "construção ideológica tecnicamente sofisticada", de que nos fala Ana Clara Torres Ribeiro:

(...) a alienação territorial, racionalizadora do corte excludente entre estratos sociais, corresponde à influência do economicismo e do pragmatismo na interpretação da experiência social. A alienação territorial é formada, portanto, por uma construção ideológica tecnicamente sofisticada, que abstrai a co-presença e conduz à acomodação incondicional aos objetivos da ação hegemônica, a única considerada racional (RIBEIRO, 2005, p.267).

O resultado mais trágico, neste território alienado, é que "Os ajustes do espaço herdado às novas condições gerais da produção, juntamente com a adesão ideológica do mercado, geram estruturas espaciais que impedem conquistas sociais" (RIBEIRO, 2005, p.267).

O desafio está mais do que posto. Urge repensarmos e alcançarmos um território noutras condições, um território fundado naquilo que de fato existe para todos, analisado e valorizado em função da existência de todos - na complexidade dos seus usos, na multiplicidade de seus objetos, ações e gentes, e, sobretudo, um território que contemple todas as possibilidades ainda não realizadas, capaz de abrigar diferentes projetos. O entendimento profundo do território usado “(...) é, pois, fundamental para afastar o risco de alienação, o risco da perda do sentido da existência individual e coletiva, o risco de renúncia ao futuro" (SANTOS, 1994, p.15).

\section{TERRITÓRIO USADO - EXISTÊNCIA E OS DESAFIOS DA LIBERDADE}

Ainda que a alienação do território se estabeleça no mundo globalizado como um sistema, há como reconhecermos também a possibilidade de superarmos o "reino da necessidade" e reencontrarmos lugar para idéias e projetos outros, que constituam caminhos possíveis para a construção de um território livre, ou seja, o almejado retorno do território para a nação, o seu funcionamento orientado para os anseios endógenos e para os interesses da maioria. Em outras palavras, alienação territorial, modernidade perversa e razão instrumental não colonizam todas as ações e não alcançam todos os lugares.

Como a ação do capital é seletiva e a dimensão do espaço econômico muito mais estreita e restrita do que aquela do espaço banal (SANTOS, 1996), só 
uma análise que contemple o espaço geográfico como um todo é capaz de reconhecer a complexidade do território usado e a riqueza de situações onde somos capazes de encontrar, para além de um uso do território estrategicamente pensado em função da acumulação vantajosa de agentes seletos, outras possibilidades de vida se realizando lá onde o território funciona e é tomado como um abrigo (SANTOS, 2000), possibilidades estas que deveriam figurar como alvo de amparo e proteção do Estado, ainda que isso no mais das vezes não se realize.

Quando procedemos a uma análise do território do modo como ele é constituído, quando analisamos os sistemas de atividades se realizando, da forma como eles existem no território, reconhecemos que, na cidade ou no campo, o valor e a importância dos homens é resultado também do lugar onde se habita (SANTOS, 2007); ou ainda, quando reconhecemos as desigualdades regionais no interior da nação, a precarização ou obsolescência de regiões e de cidades (e a total desatenção da nação a tais problemas), é de um uso desigual do território que se trata - uma desigualdade de agentes e ações, uma desigual distribuição dos recursos, uma apropriação e uso também muito desiguais da riqueza da nação (gerada pelo trabalho de todos). Tudo isso implica uma questão política, todos estes problemas revelam e reafirmam o fundamento político que o território e os seus usos encerram (KAHIL, 2005).

No entanto, e do mesmo modo como "a sociedade é mais que a economia" (SANTOS, 2007, p.121), o território precisa ser visto como algo além de um recorte estático ou de um conteúdo (ou extensão) a ser apropriado. A dimensão política do território precisa ser compreendida como algo maior do que a política hegemônica que dá conta apenas da manutenção da produção econômica globalizada que atualmente privilegia e promove a concentração da riqueza, aprofundando as desigualdades territoriais, a fragmentação e a exclusão.

Quando procedemos a uma análise crítica do espaço geográfico, ou seja, quando tomamos a totalidade de seu uso, quando consideramos o espaço de todos, o espaço banal, reconhecemos as potências realmente transformadoras, que se abrigam tantas vezes naquilo que é considerado residual, nos conte- údos tecnicamente ultrapassados e que figuram como obsoletos, nas ações e nos usos tantas vezes compreendidos como "irracionais" (SILVEIRA, 2007). Estas forças transformadoras podem ser encontradas nas sociedades dos países pobres que, marginalizadas e postas à parte das vantagens da globalização hegemônica, se organizam em outras bases para repensar uma política que verdadeiramente atenda a todos, uma política que, para além dos espaços das redes e dos macro-atores do período, seja de fato endereçada ao território como um todo.

Ainda que reconheçamos toda a dificuldade de superarmos as atuais práticas alienadas e alienantes, meta do projeto capitalista hegemônico para o uso do território como recurso (e que tantas vezes nos parece como algo inexorável ao futuro), é necessário também que reconheçamos o homem não apenas como um ser passivo, reflexo condicionado pelo atual sistema econômico. É no enfrentamento cotidiano das imposições à vida no lugar, e a partir da existência e da insistência ao enfrentamento das tantas condições antagônicas (sobretudo entre os mais pobres), que uma tomada de consciência pode vir a oferecer um entendimento e uma superação da alienação territorial, demonstrando que, na verdade, as práticas perversas do período não são irreversíveis (SANTOS, 2000), fazendo emergir, daí, uma política capaz de oferecer um novo horizonte e uma nova condição para a vida.

Para Milton Santos (1999, p.21), os saberes do lugar (criativos e necessários ao enfrentamento das condições de escassez), conjunto de práticas nutridas pelo cotidiano dos "de baixo" (as classes mais pobres, as regiões marginalizadas, as nações mais subordinadas), é a ponte para a produção desta nova Política. Política e saberes estes que poderão se opor à "política" restrita que hoje é feita, no mais das vezes, única e exclusivamente para a realização da economia hegemônica. Esta nova Política, estes saberes e esta consciência que resultam da experiência de escassez, alimentados pela compreensão totalizadora da existência e libertos que são das ideologias perversas que mantém ativo este "reino da necessidade", poderão servir como fundamentos para a construção de um território livre, e o território nacional poderá, quiçá, fundar-se como uma verdadeira "federação de lugares" (SANTOS, 1996, 1999). "Acontece, nos lugares, a 
resistência ao localismo que destina aos pobres a cidadania restrita e limitada. Neles, também é possível reconhecer rugosidades impeditivas das localizações ansiadas pela ação hegemônica, o que alimenta a noção de território que deverá substituir a que orienta esta ação" (RIBEIRO, 2004, p.44).

Nosso desafio político é que o território deixe de ser usado como um recurso vantajoso apenas aos agentes hegemônicos, para que a sociedade, organizada a partir de uma base territorial comum e a partir de interesses comuns nos lugares, possa efetivamente fazer suas escolhas, definir suas próprias vontades, propor seu próprio futuro. Uma refundação da política e uma necessária redefinição do Estado serão condições para que a ação libertária possa emergir como práxis verdadeiramente revolucionária, onde há lugar para a construção de uma nação soberana e um território mais justo para todos. As idéias de Milton Santos reconhecem tais possibilidades - "O mundo de hoje permite uma outra percepção da história, por meio da constituição de uma universalidade empírica. Sua dialética com as particularidades encorajará a superação das práxis invertidas e a possibilidade de ultrapassar o reino da necessidade, abrindo lugar para a utopia e para a esperança" (SANTOS, 2008, p.5).

\section{REFERÊNCIAS:}

BERNARDES, A. M., et al. O papel ativo da geografia: um manifesto. Florianópolis: Laboplan-USP, 2000.

CATAIA, M. A alienação do território - o papel da Guerra Fiscal no uso, organização e regulação do território brasileiro. In: SOUZA, M. A. A. de Org. Território Brasileiro: usos e abusos. Campinas: Territorial, 2003. Cap.23. p.397-416.

COSTA, W. M. Geografia Política e Geopolitica: discursos sobre o território e o poder. São Paulo: Hucitec, 1992.

HORKHEIMER, M. Do problema da previsão nas ciências sociais. In: Teoria crítica: uma documentação (Tomo I).. São Paulo: Perspectiva, 2006 [1933]. Cap. 5 p.89-94.
ISNARD, H. O espaço geográfico. Coimbra: Livraria Almedina, 1982.

KAHIL, S. P. Usos do território: uma questão política. In: X ENCONTRO NACIONAL DE GEÓGRAFOS DA AMÉRICA LATINA. São Paulo, março de 2005. Anais... São Paulo, 2005, p.7193-7204.

MARX, K. Trabalho estranhado e propriedade privada. Manuscritos econômico-filosóficos. São Paulo: Boitempo Editorial, 2008 [1844].

PORTO-GONÇALVES, C. W. Da geografia às geo-grafias: um mundo em busca de novas territorialidades. In: CECEÑA, A. E.; SADER, E. Org.. A Guerra infinita: hegemonia e terror mundial. Petrópolis: Vozes, 2002. Cap. 10, p. 289-358.

RAFFESTIN, C. Por uma geografia do poder. São Paulo: Ática, 1993.

RIBEIRO, A. C. T. Lugares dos saberes: diálogos abertos. In: BRANDÃO, Maria de Azevedo Org. Milton Santos e o Brasil. São Paulo: Perseu Abramo, 2004, p.39-49.

Outros territórios, outros mapas. OSAL. Observatório Social da América Latina. Buenos Aires, n.16, p.263-272. 2005.

SANTOS, M. O retorno do território. In: SANTOS, M.; SOUZA, M. A. A.; SILVEIRA, M. L. Org. Território: Globalização e Fragmentação. São Paulo: Hucitec, 1994, p.15-20.

. A Natureza do Espaço. Técnica e Tempo. Razão e Emoção. São Paulo: Hucitec, 1996.

O território e o saber local: algumas categorias de análise. Cadernos IPPUR. Rio de Janeiro, ano XIII, n.2, p.15-26, 1999.

. Por uma outra globalização: do pensamento único à consciência universal. Rio de Janeiro: Record, 2000. 
. Espaço e dominação: uma abordagem marxista. Economia espacial: Críticas e alternativas.. São Paulo: Hucitec, 2003 [1975], Cap.5 p.137-164.

. O espaço do cidadão. São Paulo: Edusp, 2007 (1987).

- A revolução tecnológica, a experiência da escassez e os limites da globalização atual. (Conferência de recebimento do título de Doutor Honoris Causa, UnB, 1999). Disponível em < http://www.unb.br/unb/ titulos/milton_santos.php $>$. Acesso: out, 2008.

SANTOS, M.; SILVEIRA, M. L. O Brasil: território e sociedade no início do século XXI. Rio de Janeiro: Record, 2001.

SARTRE, J-P. Questão de Método. São Paulo/Rio de Janeiro: Difel, 1979.

SILVEIRA, M. L. A região e a invenção da viabilidade do território. In: SOUZA, M. A. A. Org. Território Brasileiro: usos e abusos. Campinas: Edições Territorial, 2003. Cap. 24, p.408-416.
. O espaço geográfico: da perspectiva geométrica à perspectiva existencial. Geousp. n.19, São Paulo, p.81-91, 2006.

. Os confines de la racionalidad: el espacio geográfico contemporáneo. In: XI ENCUENTRO DE GEÓGRAFOS DE AMÉRICA LATINA, Bogotá, março de 2007. Anais...17p. Bogotá, 2007.

Um território, uma região: quando o tempo desmancha as coerências... Ciência Geográfica. Ano XIII, v. XIII, n.1. Bauru, p.24-30, jan./jun. 2008.

TEIXEIRA, F. Desconstrução da luta de classes, construção da obediência. In: TEIXEIRA, F.; FREDERICO, C. Org. Marx no século XXI. São Paulo: Cortez, 2008. Cap. 3, p.114-139.

VALLAUX, C. Geografie sociale: le sol et l'état. Paris : Octave Doin et Fils Editeurs, 1911.

WETTSTEIN, G. Subdesenvolvimento e Geografia. São Paulo: Contexto, 1992. 